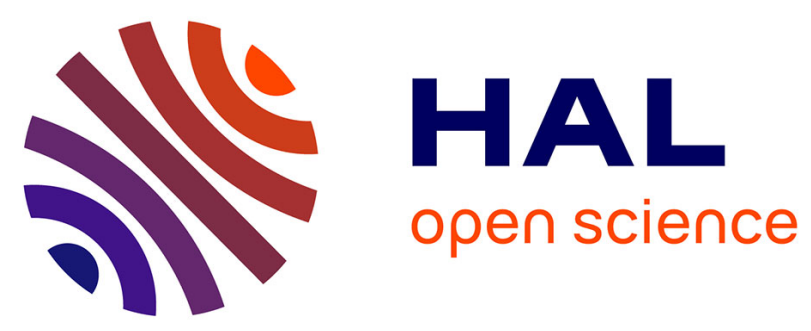

\title{
Mindfulness May Moderate the Relationship Between Intrinsic Motivation and Physical Activity: A Cross-Sectional Study
}

\author{
Alexis Ruffault, Marjorie Bernier, Nicolas Juge, Jean F. Fournier
}

\section{To cite this version:}

Alexis Ruffault, Marjorie Bernier, Nicolas Juge, Jean F. Fournier. Mindfulness May Moderate the Relationship Between Intrinsic Motivation and Physical Activity: A Cross-Sectional Study. Mindfulness, 2016, 7 (2), pp.445-452. 10.1007/s12671-015-0467-7 . hal-01317534

HAL Id: hal-01317534

https://hal.science/hal-01317534

Submitted on 18 May 2016

HAL is a multi-disciplinary open access archive for the deposit and dissemination of scientific research documents, whether they are published or not. The documents may come from teaching and research institutions in France or abroad, or from public or private research centers.
L'archive ouverte pluridisciplinaire HAL, est destinée au dépôt et à la diffusion de documents scientifiques de niveau recherche, publiés ou non, émanant des établissements d'enseignement et de recherche français ou étrangers, des laboratoires publics ou privés. 
Mindfulness may moderate the relationship between intrinsic motivation and physical activity: A cross-sectional study

Alexis Ruffault ${ }^{1,2, *}$

Marjorie Bernier ${ }^{3}$

Nicolas Juge ${ }^{4}$

Jean F Fournier ${ }^{2}$, a

${ }^{1}$ Laboratoire de Psychopathologie et Processus de Santé (EA 4057), Université Paris Descartes, Sorbonne Paris Cité, Paris, France

${ }^{2}$ Département de la Recherche, Institut National du Sport (INSEP), Paris, France

${ }^{3}$ Laboratoire Interdisciplinaire de Recherche sur les Transformations des Pratiques

Éducatives et des Pratiques Sociales (EA 7313), Université Paris-Est Créteil Val De Marne, Créteil, France

${ }^{4}$ Mindeval, Québec, Canada

${ }^{\text {a }}$ Present address: Institut National du Sport du Québec, Montréal, Canada

${ }^{*}$ Corresponding author.

Address: Laboratoire de Psychopathologie et Processus de Santé (EA 4057), Institut de Psychologie, Université Paris Descartes, 71 avenue Edouard Vaillant, 92100 BoulogneBillancourt, France

Email: alexis.ruffault@parisdescartes.fr

\section{Acknowledgements}

Lise Anhoury (French Institute of Sport) and Joan Tihy (University of Caen) for the data collection. Nelly Erichot (Paris Descartes University) and Christophe Gernigon (Univeristy of Montpellier) for various comments on the manuscript. Catherine O'Malley and Laura Killian for translation corrections. 


\begin{abstract}
This study aims to characterize the relationships between intrinsic motivation towards physical activity, mindfulness, and physical activity level. We measured self-reported mindfulness, motivational regulation towards exercise, and physical activity level in 280 French students. Analyses conducted on 244 participants revealed that self-reported mindfulness moderates the relationship between intrinsic motivation towards exercise and physical activity levels. These findings may have implications for interventionists seeking to promote increased physical activity with mindfulness-based techniques. In fact, it seems that increasing mindfulness skills of individuals could improve their intrinsic motivation to exercise and thus, physical activity.
\end{abstract}

Keywords: Health behavior; Physical activity; Motivation; Mindfulness; Students 


\section{Introduction}

The World Health Organization (2010) considers the lack of physical activity (PA) as the fourth leading risk factor of mortality in the world, and reported that sedentarity affects 60 per cent of the world population. Several researchers have come to the conclusion that a sedentary lifestyle increases health risks for conditions such as cancer (Ramírez, Finney Rutten, Vanderpool, Moser, \& Hesse, 2013), obesity, diabetes (Keadle, 2012), and heart disease (Lloyd-Jones et al., 2010). Thus, Orrow, Kinmonth, Sanderson, and Sutton (2012) recommended the promotion of PA to reduce these health risks. To this end, Biddle and Mutrie (2008) argued that the promotion of PA should include cognitive-behavioral principles of behavior change. Two principal cognitive-behavioral parameters of PA promotion examined in the recent literature are intrinsic motivation (Deci \& Ryan, 1985) and dispositional mindfulness (DM) (Brown \& Ryan, 2003).

Exploring the associations between mindfulness and health behaviors, Roberts and Danoff-Burg (2010), Gilbert and Waltz (2010), and Murphy, Mermelstein, Edwards, and Gidycz (2012) have shown that students who report higher scores of self-reported mindfulness are more likely to practice healthy habits such as getting enough sleep, eating well, and exercising compared to less mindful individuals. With obese individuals, studies have shown that an Acceptance and Commitment Therapy (ACT) program based on workshops helping participants to change their approach to their thoughts and emotions about obesity, and to accept them, resulted in lower psychological distress, greater weight loss and an increase in PA (Lillis, Hayes, Bunting, \& Masuda, 2009; Tapper et al., 2009). Thus, by becoming aware of their thoughts, emotions, and sensations due to behavior change, and by accepting them, individuals showed heightened awareness of good health behavior (Dutton, 2008). On the other hand, Mothes, Klaperski, Seelig, Schmidt, and Fuchs (2014) have shown in a randomized controlled trial that an aerobic exercise intervention increased self-reported mindfulness in men.

In the promotion of PA most especially, the literature showed the beneficial effects of mindful exercises (e.g., Yoga and Feldenkrais) (Netz \& Lidor, 2003; Salmon, Lush, Jablonski, \& Sephton, 2009) and acceptance- and mindfulness-based methods to increase mindfulness and PA levels (Butryn, Forman, Hoffman, Shaw, \& Juarascio, 2011; Chatzisarantis \& Hagger, 2007; Ulmer, Stetson, \& Salmon, 2010). While most of these studies could not draw conclusions with regards to the maintainance of the recommended PA level, Ulmer et al. (2010) showed that highest scores of mindfulness and acceptance are linked to a long term PA increase and maintenance, and conclude that "mindfulness and acceptance facilitate the relapse prevention in those who have succesfully initiated an exercise regimen" (p.808).

In the behavior change motivation literature, great attention has been paid to SelfDetermination Theory (SDT; (Deci \& Ryan, 1985). This meta-theory postulates that human behaviors are autonomous, or self-determined. Thus, to satisfy their three universal basic psychological needs (i.e., need for autonomy, for competence, and for relatedness), individuals have to change their behaviors in an autonomous way. On the autonomy continuum, there are three kinds of motivation: (a) intrinsic motivation, when one changes for enjoyment or pleasure, (b) extrinsic motivation, when one expects something in exchange for his/her behavior, which is composed of four kinds of regulation (i.e., integrated, identified, introjected, and external), and (c) amotivation, which is the absence of intentionality (Hagger \& Chatzisarantis, 2007). According to Deci and Ryan (1985), when acting in an autonomous way (i.e., with intrinsic motivation or with identified regulation), one satisfies his/her three basic psychological needs.

Context, social factors and environmental factors modulate self-determined motivation. Thus, one could change his/her PA habits if this new behavior procures pleasure, satisfaction, 
and if he/she values and places importance on this new behavior (Ryan \& Deci, 2000). This means he/she knows that a recommended PA level will be healthy and without constraints. Several studies have investigated the effects of SDT-based interventions on the increase of PA level (Hagger \& Chatzisarantis, 2007). The main findings of these studies were that PA levels and intrinsic motivation increased (Fortier, Sweet, O'Sullivan, \& Williams, 2007; Jolly et al., 2009), and participants of the SDT-group better satisfied they basic psychological needs (Edmunds, Ntoumanis, \& Duda, 2008).

For the promotion of PA, studies have investigated the effects of a mindfulness-based intervention or an SDT-based intervention, and measured mindfulness or SDT outcomes respectively. In the original texts of SDT (Deci \& Ryan, 1985) and DM (Brown \& Ryan, 2003), some links between mindfulness and intrinsic motivation are central to both of these theories. Levesque and Brown (2007) highlighted the agreement between both theories by arguing that: (a) in SDT, awareness facilitates self-regulated functioning, and (b) selfreported mindfulness predicts higher levels of self-regulated behavior. This highlights the suggested links between mindfulness and motivation, although these links have never been empirically tested. Thus, we expect some common mecanisms in SDT and mindfulness related to self-regulation. Rigby, Schultz, and Ryan (2014) suggested theoretical links between mindfulness and SDT. For each motivational regulation, the authors explained how mindfulness and motivation are linked through the self-determination continuum. Moreover, Butryn et al. (2011) argued that the relationship between DM and PA could be related to motivation to engage in such behavior. Tsafou, DeRidder, vanEe, and Lacroix (2015) showed that satisfaction (i.e., an intrinsic motive) is a predictor of the effects of self-reported mindfulness on PA behavior.

So it is known that both motivational regulation and mindfulness skills favor higher PA levels, separately. Thus, mindfulness could either moderate or mediate the relationship between intrinsic motivation and PA level. Likewise, intrinsic motivation could either moderate or mediate the relationship between self-reported mindfulness and PA level, or selfreported mindfulness and intrinsic motivation could both be linked to PA level with neither moderation nor mediation types of relationships. Our study aims to characterize the relationships between intrinsic motivation relative to PA, mindfulness, and PA level. The literature did not make it possible to hypothesize any specific model, which is why we considered five different models (see Figure 1) to determine the precise relationship among self-reported mindfulness, motivational regulation and PA level. 

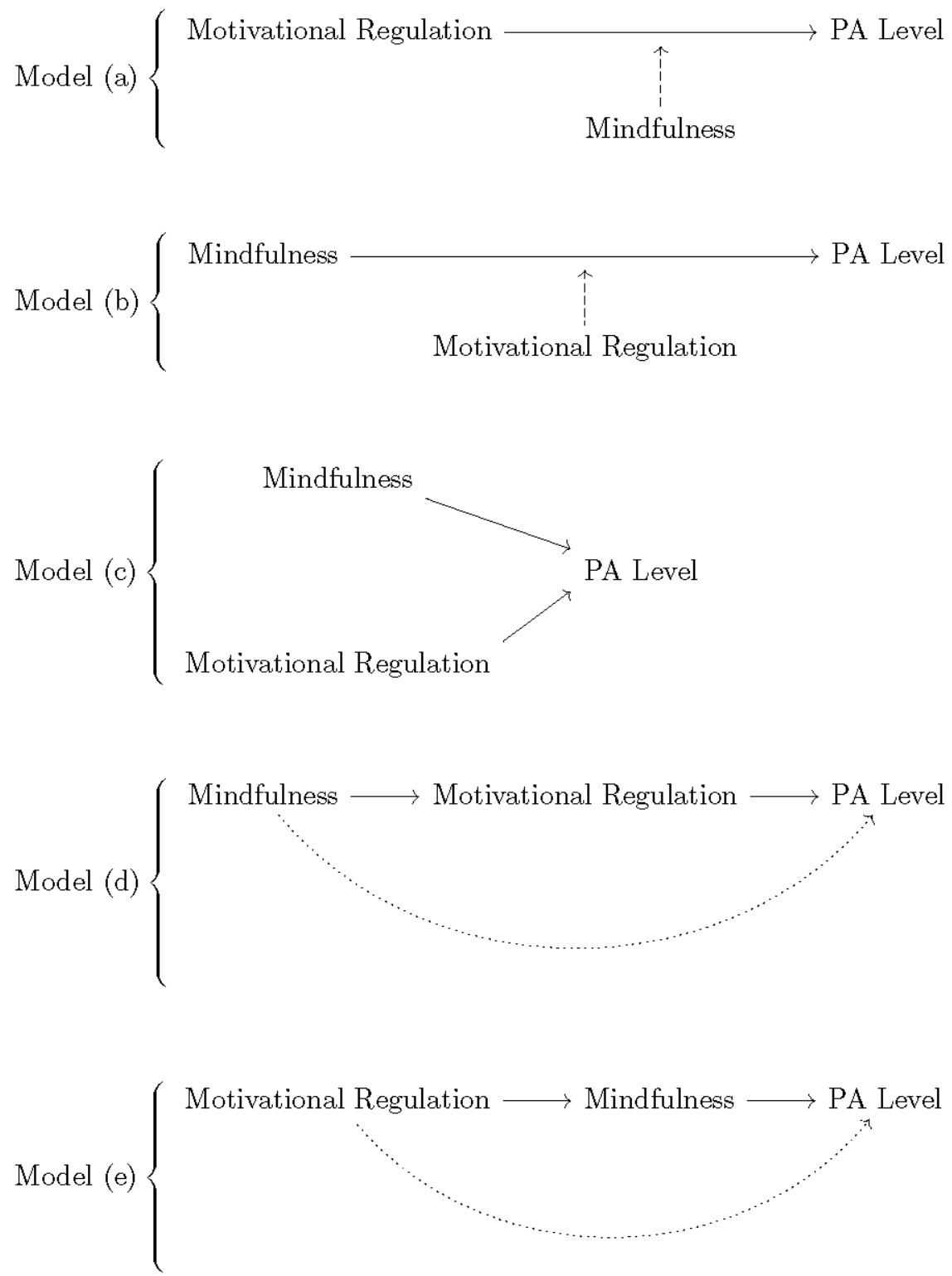

Fig. 1 Candidate models used to characterize the relationships between motivational regulation, self-reported mindfulness, and physical activity (PA) level.

Note: Model (a) represents the possible moderating effect of self-reported mindfulness in the relationship between motivational regulation and PA level. Model (b) represents the possible moderating effect of motivational regulation in the relationship between self-reported mindfulness and PA level. In model (c) self-reported mindfulness and motivational regulation are two possible independent predictive variables of PA level. Model (d) represents the possible mediating effect (full or partial) of motivational regulation between self-reported mindfulness and PA level. Model (e) represents the possible mediating effect (full or partial) of self-reported mindfulness between motivational regulation and PA level.

\section{Participants}

\section{Method}

Two hundred and eighty French students $(41.79 \%$ males and $58.21 \%$ females $)$ aged between 18 and 37 years old $(M=21 ; S D=2.73)$ with a mean body mass index (BMI) of $21.86 \mathrm{~kg} / \mathrm{m}^{2}(S D=2.81)$, were asked to fill out self-report questionnaires measuring selfreported mindfulness, motivational regulation towards exercise, and PA level. Recruitment was conducted in three different-sized university towns: Paris, Montpellier, and Caen. 


\section{Procedure}

Participants had to indicate which major they were pursuing, in which year, and whether they practiced sport regularly or not. To control for the bias of knowing the questionnaires or being extremely physically active, students in psychology and PA sciences were excluded from this study. All the participants gave their signed agreement to participate in the study. Participants were given a random code to withdraw from the study at any time after they filled out the questionnaires, upon their request. Institutional ethical approval was sought and given. Participants' characteristics are displayed in Table 1.

Table 1 Ad-hoc sample characteristics

\begin{tabular}{lcccc}
\hline Variables & $M$ & $S D$ & $\%$ & \multicolumn{1}{c}{ Range } \\
\hline Gender (\% female) & & 58.21 & \\
Age (years) & 21.00 & 2.734 & & {$[18.00 ; 37.00]$} \\
BMI (kg/m") & 21.86 & 2.813 & & {$[16.71 ; 35.93]$} \\
Major & & & & \\
$\quad$ Literature & & 31.43 & \\
$\quad$ Sciences & & 28.93 & \\
$\quad$ Law and politics & & 26.43 & \\
$\quad$ Medicine & & 13.21 & \\
School year & & & \\
$\quad$ Undergraduate & & & 76.42 & \\
$\quad$ Graduate & & 20.70 & \\
$\quad$ PhD students & & & 2.88 & \\
Sport practice (\% "yes") & \multicolumn{3}{c}{38.93} \\
\hline Mean (M); standard deviation (SD); body mass index (BMI).
\end{tabular}

\section{Measures}

To assess DM as self-reported mindfulness, the Mindful Attention Awareness Scale (MAAS) (Brown \& Ryan, 2003) was used in its French validated version. Csillik, Mahr, and Meyer (2010) adapted the French version of the MAAS, which is a single factor 15-items self-report instrument measuring the frequency of mindful states in day-to-day life. Each item is rated on a 6-point Likert scale ranging from 1 ("almost always") to 6 ("almost never"), and the score is the mean of all items, ranging from 1 (i.e., low frequency of mindful states) to 6 (i.e., high frequency of mindful states). In our sample, the French version of MAAS showed good internal consistency $(\alpha=0.78)$.

To assess the motivational regulation towards exercise, the Behavioral Regulation towards Exercise Questionnaire (BREQ-II; (Markland \& Tobin, 2004) (French version) was used. The BREQ-II is a self-report 19-item questionnaire measuring motivational regulation towards exercise. Each item is rated on a 5-point Likert scale ranging from 0 ("not true for me") to 4 ("very true for me"). This questionnaire is based on five subscales, which represent the motivational regulation of SDT: amotivation (A), external regulation (ER), introjected regulation (ITR), identified regulation (IDR), and intrinsic regulation (IR). In our sample, the five subscales of BREQ-II showed good internal consistency $\left(\alpha_{\mathrm{A}}=0.79 ; \alpha_{\mathrm{ER}}=0.77 ; \alpha_{\mathrm{ITR}}=\right.$ $\left.0.72 ; \alpha_{\mathrm{IDR}}=0.74 ; \alpha_{\mathrm{IR}}=0.91\right)$.

PA level was measured with the International Physical Activity Questionnaire (IPAQ; (Craig et al., 2003). The French version of the IPAQ is a widely used self-report 7-items measure of PA level (Keadle, 2012; Ulmer et al., 2010). It provides information on the participants' time spent walking and doing vigorous and moderate physical activities during the past seven days (if not representative of the perceived average PA, participants were asked to think about the most representative past 7-day time frame). The unit of this measure 
is an overall energy expenditure expressed in Metabolic Equivalent Total (MET). In short, the IPAQ calculations are: Walking MET-min/week $=3.3 \times$ walking minutes $\times$ walking days; Moderate MET-min/week $=4.0 \times$ moderate-intensity activity minutes $\times$ moderate days; Vigorous MET-min/week $=8.0 \times$ vigorous-intensity activity minutes $\times$ vigorous-intensity days. Total PA MET-min/week = sum of Walking + Moderate + Vigorous MET minutes. The total MET-min per week was used as a continuous indicator for PA.

\section{Data Analyses}

The data were analysed on $\mathrm{R}$ (R Core Team, 2013) after exclusion of the participants who did not reply to the questionnaires entirely $(\mathrm{n}=33)$ and participants who did not respect the IPAQ guidelines $(n=3)$ (Craig et al., 2003). Thus, correlational analysis and hierarchical regression analyses were run on 244 participants. The dependant variable in the models is the IPAQ scores, and we tested the predictive properties of intrinsic motivation (according to BREQ-II subscale) in step 1, self-reported mindfulness in step 2 (simple linear regression model), and the moderation or the mediation between intrinsic motivation and self-reported mindfulness in step 3. Mean scores and correlational statistics are displayed in Table 2. The non-parametric Kendall correlation test was used because it does not rely on any asumptions about the underlying distributions (BREQ sub-scales do not have a normal distribution).

We defined the PA level variable as the $\log _{2}$ of the IPAQ score. This choice was motivated by the nature of the IPAQ scoring as METs roughly double when the perceived PA intensity increases by 1 (from low, to moderate, to vigorous). Moreover, the distribution of the PA levels has the property of being normally distributed, in contrast to the raw IPAQ scores (e.g., Rzewnicki, Auweele, \& De Bourdeaudhuij, 2003).

\section{Results}

Preliminary analyses were conducted to ensure no violation of the assumptions of normality, linearity, and homoscedasticity. Models (b), (d) and (e) were discarded because of the absence of significant correlation between self-reported mindfulness and PA level (see Table 2), which indicated that self-reported mindfulness could not be a predictor of PA level (Baron \& Kenny, 1986). Only two models remained: the moderation model (a) and the simple linear model (c), which represents the main effect of the moderation model. Model (c) was tested at step 2. Plotting the Pearson residuals enabled us to check the normality of their distribution. The basic assumptions for a multiple regression analysis were satisfied.

As expected, self-reported mindfulness showed positive correlations to the automous motivational regulations (i.e., intrinsic and identified), and negative to the controlled motivational regulations (i.e., external and amotivation) (see Table 2). PA level showed positive significant correlations to the autonomous motivational regulations; such as intrinsic $(\tau=.21 ; p<.001)$, identified $(\tau=.20 ; p<.001)$. In contrast, PA level was negatively correlated with external regulation $(\tau=-.06 ; n s)$ and amotivation $(\tau=-.22 ; p<.001)$. In our sample, BMI showed no significant correlation to any other variable. 
Table 2 Descriptive and correlational statistics

\begin{tabular}{|c|c|c|c|c|c|c|c|c|c|c|c|c|}
\hline \multirow[b]{2}{*}{ Variables } & \multicolumn{4}{|c|}{ Descriptive statistics } & \multicolumn{8}{|c|}{ Correlations } \\
\hline & Mean & $S D$ & $\begin{array}{c}\text { Possible } \\
\text { range }\end{array}$ & Observed range & 1 & 2 & 3 & 4 & 5 & 6 & 7 & 8 \\
\hline 1. Mindfulness & 3.78 & 0.672 & {$[1 ; 6]$} & {$[2.13 ; 5.8]$} & & $.17 *$ & $.11 *$ & .01 & $-.11 *$ & $-.25^{*}$ & .04 & .02 \\
\hline 2. Intrinsic regulation & 3.02 & 1.085 & {$[0 ; 4]$} & {$[0 ; 4]$} & & & $.51 *$ & $.12 *$ & $-.25 *$ & $-.46^{*}$ & $.21 *$ & -.02 \\
\hline 3. Identified regulation & 2.82 & 0.900 & {$[0 ; 4]$} & {$[0 ; 4]$} & & & & $.41^{*}$ & $-.11 *$ & $-.43 *$ & $.20^{*}$ & .06 \\
\hline 4. Introjected regulation & 1.51 & 1.102 & {$[0 ; 4]$} & {$[0 ; 4]$} & & & & & $.11 *$ & $-.15^{*}$ & $.16^{*}$ & .08 \\
\hline 5. External regulation & 0.40 & 0.633 & {$[0 ; 4]$} & {$[0 ; 3.5]$} & & & & & & $.23 *$ & -.06 & .06 \\
\hline 6. Amotivation & 0.44 & 0.758 & {$[0 ; 4]$} & {$[0 ; 3.75]$} & & & & & & & $-.22 *$ & .02 \\
\hline 7. Physical activity & 11.32 & 1.20 & & {$[5.63 ; 14.62]$} & & & & & & & & .06 \\
\hline 8. BMI & 21.84 & 2.797 & & & & & & & & & & \\
\hline
\end{tabular}

${ }^{*} p<.05$; standard deviation $(S D)$. Correlation coefficients are non-parametric Kendall's Tau. Pysical activity scores are log 2 (IPAQ). BMI scores are in $\mathrm{kg} / \mathrm{m}^{2}$.

Table 3 Hierarchical regression analyses reporting the variance in physical activity level explained by dispositional mindfulness and intrinsic motivation

\begin{tabular}{|c|c|c|c|c|c|c|c|c|c|}
\hline Step & Independent variable & $R^{2}$ & $\begin{array}{c}R^{2} \\
\text { change }\end{array}$ & $B$ & $B S E$ & $\beta$ & $\beta S E$ & $t$ & $F$ \\
\hline 1 & Intrinsic motivation & $.10 * * *$ & & .36 & .07 & $.32 * * *$ & .06 & 5.32 & 28.26 \\
\hline 2 & Mindfulness & $.10 * * *$ & .00 & .01 & .11 & $<.01$ & .06 & .12 & 14.08 \\
\hline 3 & Intrinsic motivation $\times$ Mindfulness & $.12 * * *$ & .02 & -.23 & .11 & $-.14 *$ & .07 & -2.02 & 10.88 \\
\hline
\end{tabular}

$* p<.05 ; * * p<.01 ; * * * p<.001$

$R^{2}$, the proportion of the criterion variance explained by predictors over and above response; $R^{2}$ change, the difference between $R^{2}$ in step by step regression; $B$, unstandardized regression coefficients; $S E$, standard error; $\beta$, standardized regression coefficients 
The moderation model (a) is displayed in step 3 in Table 3. At step 2, self-reported mindfulness was not a significant predictor of PA level. The moderation model explained the greatest variance in PA level $\left(R^{2}=11.97 \% ; F(3,240)=10.88 ; p<.001\right)$. This model followed (Baron \& Kenny, 1986) criteria for a moderation effect, with self-reported mindfulness as moderator of the predicting effect of intrinsic motivation on PA level. At step 3 , intrinsic motivation was a significant predictor of PA level $(\beta=.29 ; t=4.54 ; p<.001)$, while self-reported mindfulness did not significantly predict PA level $(\beta=.02 ; t=.39 ; n s)$, and the interaction between intrinsic motivation and self-reported mindfulness was a significant predictor of PA level $(\beta=-.14 ; t=-2.02 ; p<.05)$. Moreover, ANOVA between models at each step showed that the model at step 3 had a significant change in $R^{2}$ from the linear model at step $2\left(R^{2}\right.$ change $\left.=.02 ; F(1,240)=4.11 ; p<.05\right)$. Figure 2 illustrates the moderating effect of self-reported mindfulness between intrinsic motivation and PA level. Participants were split into three distinct groups of self-reported mindfulness levels:

a. participants with self-reported mindfulness scores below the mean minus 1 standard deviation (crosses);

b. participants with self-reported mindfulness scores distant from the mean by no more than 1 standard deviation (triangles);

c. participants with self-reported mindfulness scores greater than the mean plus 1 standard deviation (squares).

In this graphic, we see that when self-reported mindfulness is low, intrinsic motivation is not related to PA level. But, as self-reported mindfulness increases, the link between instrinsic motivation and PA levels becomes positively correlated and much stronger. 


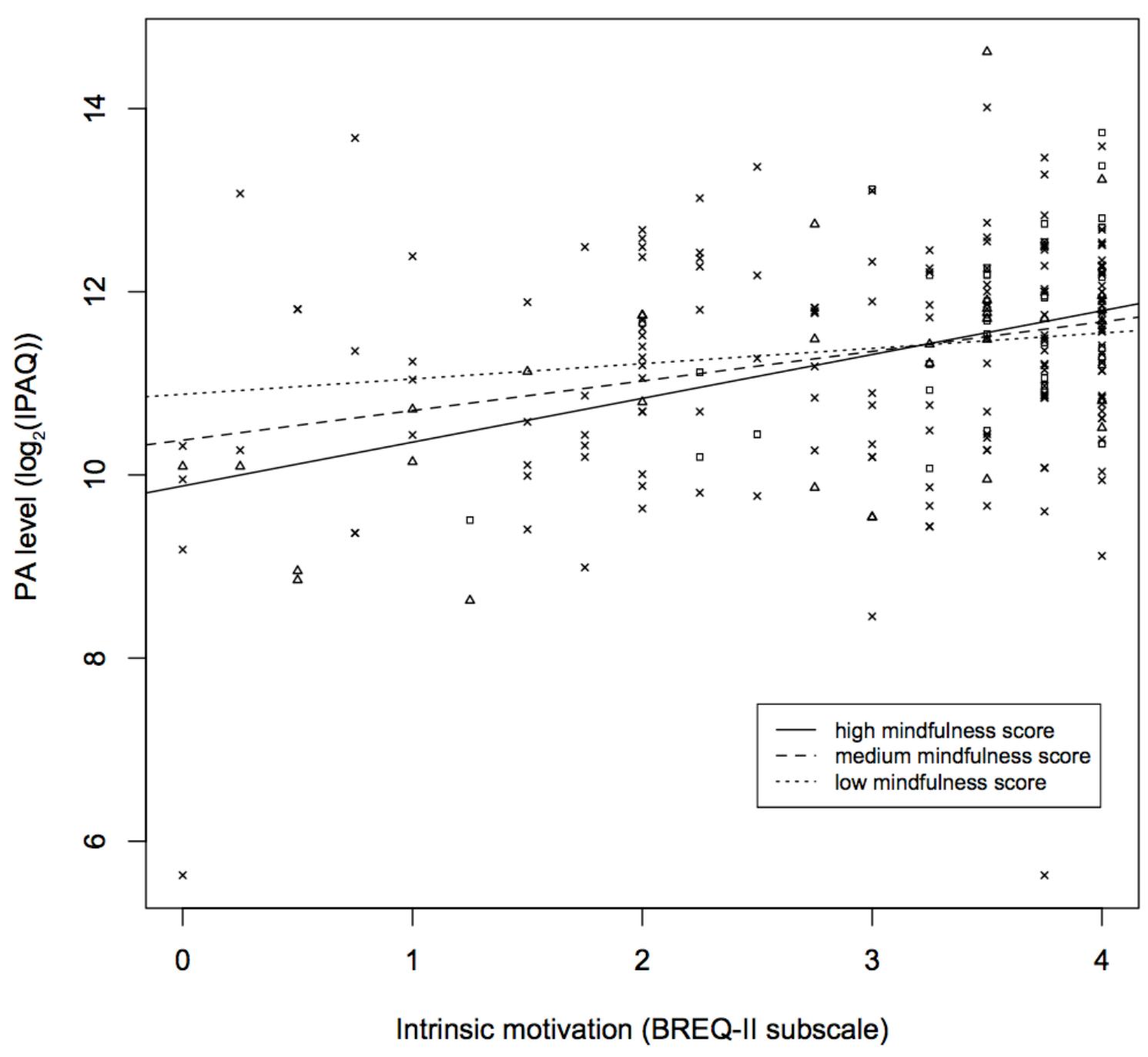

Fig. 2 Moderating effect of self-reported mindfulness on the relationship between intrinsic motivation and physical activity (PA) level

Note: On the y-axis, PA level is the $\log _{2}$ of the IPAQ score. A high self-reported mindfulness score (greater than $+1 S D$, in squares) leads to a stronger relationship between intrinsic motivation and PA level compared to a medium self-reported mindfulness score (in triangles) or a low self-reported mindfulness score (lower than $-1 S D$, in crosses).

\section{Discussion}

The aim of this study was to characterize the relationships among intrinsic motivation towards PA, mindfulness, and PA level. Theoretical links between mindfulness and motivation have been described in original research in these fields (Brown \& Ryan, 2003; Deci \& Ryan, 1985), but no empirical evidence has been found. Most studies investigated the relationships between motivation and PA level (Hagger \& Chatzisarantis, 2007) or between mindfulness and PA level (Butryn et al., 2011; Ulmer et al., 2010), resulting in an association of higher PA levels in individuals with higher intrinsic motivation on the one hand, and higher mindfulness skills on the other. To our knowledge, this study is the first to try to empirically test the links suggested in previous works (Brown \& Ryan, 2003; Deci \& Ryan, 
1985; Levesque \& Brown, 2007; Rigby et al., 2014) among the three variables (i.e., DM, intrinsic motivation, PA level). The correlation data we obtained from an ad-hoc sample of 244 students across three French cities enabled us to propose a model explaining the relationship among intrinsic motivation towards PA, self-reported mindfulness, and PA level. Motivation regulation subscales showed a high proportion of low levels of amotivation and external regulation, stable distribution of introjected regulation, and high proportions of high levels of identified and intrinsic regulations. All these tendencies are in accordance with SDT. In fact, when more intrinsically motivated, one is more autonomous (Deci \& Ryan, 1985). These tendencies may be specific to the youthful characteristic of the population that we studied, and may differ from the general population. Hagger and Chatzisarantis (2007) argued that motives such as appearance and weight are autonomous. We know that adolescents and young adults are more likely to be interested in their body image. This could explain the dispersion of the BREQ-II scores.

Literature on behavior change has described the role of DM in healthy behaviors. Studies have shown that mindful individuals are more likely to engage in and maintain healthy behaviors (Roberts \& Danoff-Burg, 2010; Ulmer et al., 2010). Moreover, authors argued that self-regulation of thoughts and emotions linked to behavior change, convinced mindful individuals to change their behavior more easily than individuals with lower mindfulness skills (Levesque \& Brown, 2007). In our sample, high levels of self-reported mindfulness were associated with higher levels of intrinsic motivation, and higher levels of PA, which confirms previous work (Brown \& Ryan, 2003; Deci \& Ryan, 1985). These results suggest that DM leads to more intrinsic, and healthier behavior choices. This tendency was observed in the correlation matrix (Table 2), in which we can see that the more intrinsically motivated towards exercise participants were the more mindful.

Considering the moderation model, why would DM impact motivational regulation of PA practice? First, it is known that lacking in specific awareness leads to habitual or automatic behaviors. Brown and Ryan (2003) highlighted the reverse relationship between DM and impulsivity (i.e., automatic behavior). Studies have shown that self-reported mindfulness is linked to healthier behaviors such as exercise. This relationship could be due to better life decisions made while one is mindful (Williams \& Kabat-Zinn, 2013). Second, according to Brown and Ryan (2003), bringing an open awareness to the present experience is linked to "self-regulation". According to the authors, self-regulation leads to behavior choices that are in accordance with one's needs (i.e., SDT's universal basic psychological needs, such as autonomy). Furthermore, self-regulation and awareness appear to be central components in SDT and DM conceptualisations. Our model showed that mindfulness (i.e., specific awareness of the present experience in a non-judgemental way) and intrinsic motivation (i.e., behaviors driven more autonomously) could be effective predictors of PA, with a moderation effect of mindfulness in the relationship between intrinsically motivated intentions and actual behavior (i.e., PA). Further research investigating this relationship applied to another health-related behavior, such as diet, could be of interest. Third, ACT authors (Hayes et al., 2004) argued that awareness and acceptance of thoughts and emotions protects from experiental and cognitive avoidance, ruminations, and other cognitive distortions. In their book, Biddle and Mutrie (2008) highlighted that there might be a gap between self-perceptions of competence to change and actual competence to change. This gap could induce cognitive distortions, and being aware of it could protect individuals from these distortions. Further studies could assess perceived stress towards behavior change, and investigate the links between mindfulness skills and cognitive processes in the context of a behavior change.

However, the present study has limitations. The exclusively self-reported and subjective data limit the conclusions of the study to participants' self-perceptions. For 
example, PA level could have been measured with accelerometers providing an objective energy expenditure. Furthermore, the relationaship between motivational regulation and PA behavior could be explained with different unassessed variables such as psychopathology, time for leisure, or even environemental facilities to exercise. Another limitation is the use of a one-factor scale as a measure for mindfulness skills while a multi-scales measure could have brought more information regarding the specific facets of mindfulness implicated in the relationship between motivation and behavior. Moreover, only students with an average age of 21 years were included into this study, thus results cannot necessarily be generalized to the population at large.

In our ad-hoc sample, self-reported mindfulness had a moderating role on the relationship between intrinsic motivation towards exercise and actual PA level. The results suggest that mindful individuals are more likely to have an increased PA level while they are intrinsically motivated, and that mindless individuals have concerns in being active even if they are intrinsically motivated. It is necessary to test whether this model remains unchanged in the general population by controlling the distribution in subgroups (e.g., gender, age, occupation, income). The next stage would entail doing a true randomized experiment, testing the moderation effect of DM while controlling the mindfulness variable with a mindfulness-based intervention aiming at increasing PA level.

\section{Funding source}

None.

\section{Conflict of Interest}

None.

\section{References}

Baron, R. M., \& Kenny, D. A. (1986). The moderator-mediator variable distinction in social psychological research: Conceptual, strategic, and statistical considerations. Journal of Personality and Social Psychology, 51(6), 1173-1182.

Biddle, S., \& Mutrie, N. (2008). Psychology of physical activity: Determinants, well-being, and interventions (2nd ed.). New York, NY: Routledge.

Brown, K. W., \& Ryan, R. M. (2003). The benefits of being present: Mindfulness and its role in psychological well-being. Journal of Personality and Social Psychology, 84(4), 822-848. doi: 10.1037/0022-3514.84.4.822

Butryn, M. L., Forman, E., Hoffman, K., Shaw, J., \& Juarascio, A. (2011). A pilot study of acceptance and commitment therapy for promotion of physical activity. Journal of physical activity \& health, 8(4), 516-522.

Chatzisarantis, N. L. D., \& Hagger, M. S. (2007). Mindfulness and the intention-behavior relationship within the theory of planned behavior. Personality and Social Psychology Bulletin, 33(5), 663-676. doi: 10.1177/0146167206297401

Craig, C. L., Marshall, A. L., Sjostrom, M., Bauman, A. E., Booth, M. L., Ainsworth, B. E., . .. Oja, P. (2003). International physical activity questionnaire: 12-country reliability and validity. Medicine \& Science in Sports \& Exercise, 35(8), 1381-1395. doi: 10.1249/01.MSS.0000078924.61453.FB

Csillik, A. S., Mahr, S., \& Meyer, T. (2010). The mindful attention awareness scale (MAAS) French validation: Convergent and divergent validity. Paper presented at the Quatrième congrès international de la théorie de l'autodétermination, Gand, Belgium.

Deci, E. L., \& Ryan, R. M. (1985). Intrinsic motivation and self-determination in human behavior. New York, NY: Plenum. 
Dutton, G. R. (2008). The role of mindfulness in health behavior change. ACSM Health \& Fitness Journal, 12(4), 7-12. doi: 10.1249/FIT.0b013e31817bf5db

Edmunds, J., Ntoumanis, N., \& Duda, J. L. (2008). Testing a self-determination theory-based teaching style intervention in the exercise domain. European Journal of Social Psychology, 38(2), 375-388. doi: 10.1002/ejsp.463

Fortier, M. S., Sweet, S. N., O’Sullivan, T. L., \& Williams, G. C. (2007). A selfdetermination process model of physical activity adoption in the context of a randomized controlled trial. Psychology of Sport and Exercise, 8(5), 741-757. doi: 10.1016/j.psychsport.2006.10.006

Hagger, M. S., \& Chatzisarantis, N. (2007). Intrinsic motivation and self-determination in exercise and sport. Champaign, IL: Human Kinetics.

Hayes, S. C., Strosahl, K. D., Wilson, K. G., Bissett, R. T., Pistorello, J., Toarmino, D., . . Bergan, J. (2004). Measuring experiential avoidance: A preliminary test of a working model. Psychological Record, 54(4), 553-578.

Jolly, K., Duda, J. L., Daley, A., Eves, F. F., Mutrie, N., Ntoumanis, N., . . Williams, G. C. (2009). Evaluation of a standard provision versus an autonomy promotive exercise referral programme: Rationale and study design. BMC public health, 9, 176. doi: 10.1186/1471-2458-9-176

Keadle, S. K. (2012). The influence of free-living activity and inactivity on health outcomes and responsiveness to exercise training. $(\mathrm{PhD})$, University of Massachusetts.

Levesque, C., \& Brown, K. W. (2007). Mindfulness as a moderator of the effect of implicit motivational self-concept on day-to-day behavioral motivation. Motivation and Emotion, 31(4), 284-299. doi: 10.1007/s11031-007-9075-8

Lillis, J., Hayes, S. C., Bunting, K., \& Masuda, A. (2009). Teaching acceptance and mindfulness to improve the lives of the obese: A preliminary test of a theoretical model. Annals of Behavioral Medicine, 37(1), 58-69. doi: 10.1007/s12160-009-9083$\mathrm{x}$

Lloyd-Jones, D. M., Hong, Y., Labarthe, D., Mozaffarian, D., Appel, L. J., Van Horn, L., . . . Rosamond, W. D. (2010). Defining and setting national goals for cardiovascular health promotion and disease reduction: The American Heart Association's strategic impact goal through 2020 and beyond. Circulation, 121(4), 586-613. doi: 10.1161/CIRCULATIONAHA.109.192703

Markland, D., \& Tobin, V. (2004). A modification to the behavioural regulation in exercise questionnaire to include an assessment of amotivation. Journal of Sport and Exercise Psychology, 26(2), 191-196.

Netz, Y., \& Lidor, R. (2003). Mood alterations in mindful vers aerobic exercise modes. The Journal of Psychology, 137(5), 405-419.

Orrow, G., Kinmonth, A. L., Sanderson, S., \& Sutton, S. (2012). Effectiveness of physical activity promotion based in primary care: Systematic review and meta-analysis of randomised controlled trials. $B M J$, 344, e1389-e1389. doi: 10.1136/bmj.e1389

R Core Team. (2013). R: A language and environment for statistical computing. Vienna, Austria: R Foundation for Statistical Computing.

Ramírez, A. S., Finney Rutten, L. J., Vanderpool, R. C., Moser, R. P., \& Hesse, B. W. (2013). Correlates and geographic patterns of knowledge that physical activity decreases cancer risk. The Journal of Primary Prevention, 34(1-2), 31-39. doi: 10.1007/s10935-012-0289-5

Rigby, C. S., Schultz, P. P., \& Ryan, R. M. (2014). Mindfulness, interest-taking, and selfregulation. In A. Ie, C. T. Ngnoumen, \& E. J. Langer (Eds.), The Wiley Blackwell handbook of mindfulness (pp. 216-235): John Wiley \& Sons, Ltd. 
Roberts, K. C., \& Danoff-Burg, S. (2010). Mindfulness and health behaviors: Is paying attention good for you? Journal of American College Health, 59(3), 165-173. doi: $10.1080 / 07448481.2010 .484452$

Ryan, R. M., \& Deci, E. L. (2000). Self-determination theory and the facilitation of intrinsic motivation, social development, and well-being. American psychologist, 55(1), 68-78.

Salmon, P., Lush, E., Jablonski, M., \& Sephton, S. E. (2009). Yoga and mindfulness: Clinical aspects of an ancient mind/body practice. Cognitive and behavioral practice, 16(1), 59-72. doi: 10.1016/j.cbpra.2008.07.002

Tapper, K., Shaw, C., Ilsley, J., Hill, A. J., Bond, F. W., \& Moore, L. (2009). Exploratory randomised controlled trial of a mindfulness-based weight loss intervention for women. Appetite, 52(2), 396-404. doi: 10.1016/j.appet.2008.11.012

Tsafou, K. E., DeRidder, D. T. D., vanEe, R., \& Lacroix, J. P. W. (2015). Mindfulness and satisfaction in physical activity: A cross-sectional study in the Dutch population. Journal of health psychology, 1-11. doi: 10.1177/1359105314567207

Ulmer, C. S., Stetson, B. A., \& Salmon, P. G. (2010). Mindfulness and acceptance are associated with exercise maintenance in YMCA exercisers. Behaviour Research and Therapy, 48(8), 805-809. doi: 10.1016/j.brat.2010.04.009

Williams, J. M. G., \& Kabat-Zinn, J. (2013). Mindfulness: Diverse perspectives on its meanings, origins and applications. London: Routledge.

World Health Organization. (2010). Global recommendations on physical activity for health. Retrieved from http://whqlibdoc.who.int/publications/2010/9789241599979_eng.pdf. 